\title{
The Art of Fuli Clay Pottery in a Regional Culture Perspective
}

\author{
Hu Chenchen ${ }^{1, a, *}$ \\ ${ }^{1}$ Colledge of Elementary Education, Zaozhuang University,Zaozhuang, China \\ a304704808@qq.com \\ *corresponding author
}

Keywords: Fuli clay pottery; folk art; freehand brushwork; modeling; coloring; expression.

\begin{abstract}
The folk art resources in Zaozhuang are very rich, the variety of folk arts are quite diverse. The art of Fuli clay pottery has taken on a new spectacle under the cultural threshold. In its artistic expression language, it accumulated profound cultural connotations, traditional aesthetic conceptions and philosophical views. The art of Fuli clay pottery analyzes and grasps the cultural traits of clay pottery from three aspects: simply modeling, naturally coloring and profound expression, so as to deeply understand the shape of Chinese folk art culture and experience the traditional Chinese culture. In the rich soil of traditional culture, we should search for an inner spirit suitable for its innovation and development so that more people will pay attention to and protect the art of Fuli clay pottery. In this way, people can inherit and innovate the art and culture that belong to our nation, which has a high practical significance to the creation of Zaozhuang regional culture and systematic artistic expression.
\end{abstract}

\section{Introduction}

Many people think that the folk culture cannot compare with the profound classic culture that clay pottery made by ordinary people cannot compare with $\mathrm{Xu}$ Beihong's traditional Chinese painting or Picasso's oil painting. They think the folk culture is rough and clumsy and has no value. In fact, the existence of every kind of thing has its own special meaning. The profound culture represents a high artistic level and is created by outstanding talents while the folk culture is the collective wisdom of the common people, which represents the commonalities of ethnic groups and regions, and fully demonstrates the characteristics, level of development and aesthetic way of people from a particular region.

From the day of its birth, the Fuli clay pottery is closely related to the life of the people living in the south of Shandong Province. The Fuli clay pottery contains rich artistic elements and strong emotions, and it is also a medium for folk artists to express their inner thoughts and emotions. Although the inheritance and development of the Fuli clay pottery are influenced by various factors such as the age, region, nationality, utilitarianism, etc., we also see the efforts made by all levels of government, cultural departments and the folk artisans. We hope that the survival and development of the Fuli clay pottery can get more people's support, at the same time attract more people to protect, inherit and promote the art of Fuli clay pottery.

\section{Method}

In the Chinese philosophical thought, we can understand the existence of subjective spirit. Our ancestors prefer to express their own life experiences and humane care through the use of vivid expressions and freehand brushwork called "Xieyi", and they express themselves through the form of literature and art. People are not unfamiliar with the word "Xieyi"(which means "freehand brushwork") and it often appears in the cultural theories and classic books about painting, calligraphy, sculpture, architecture, literature and art. The interpretation of "Xieyi" in the Cihai (a dictionary) is as follows: "A technique of depicting the object through some easy but concise brushes and touches". ${ }^{[2]}$ If we interpret "Xieyi" word by word, we can see that "Xie" usually 
focusing on the artist's performance skills and methods of artistic creation. "Yi" is to express the real feelings of creators, to show their own aesthetic point of view and aesthetic orientation. By using the technique of "Xieyi", the artists pay more attention to the expression of inner feelings, but at the same time they also pursue the performance of skills.

In Lintao, Gansu Province, a piece of pottery painted with "wolf pattern" was unearthed. It is an example of freehand brushwork on the surface of pottery. The archeologists confirmed that this color clay pot belongs to Xindian culture type, about 2800 years ago. The pattern on the clay pot does not obey the symmetry, but simple and smooth, which makes the whole clay pot full of freehand style. Among the Fuli clay pottery art works, there are also many works that are characterized by their artistic quality of being freehand brushwork. The potteries using monster patterns make use of exaggerated techniques, and the morphological portrayal does not rigidly adhere to the accuracy of modeling, but they ultimately display the artistic features. The works of animals that looked up and open the mouth demonstrate the image of a ferocious animal. The finishing touch of the entire pottery is by using two small round lumps as the monster's eyes, which makes it like a real monster sitting here. The monster pottery displays a wild nature but with a rustic beauty. Although the proportion of its shape is not realistic, it has the similar characteristics as a real monster.

\subsection{Modeling — Simple and Live}

With the development of the times and economy, the functions of pottery are no longer confined to practical functions. The most obvious feature is the appearance of ornamentation and patterns in pottery, which demonstrates the aesthetic characteristics. The Fuli clay pottery is the most important folk art form in Shandong Province during the middle period of the Dawenkou Culture. Its progress and evolution contain the wisdom of people. The Fuli clay pottery art relies on mud, fire and other media to express the texture of works, creators' subjective feelings and their own cultural meanings. What is very interesting is that from the north to the south of China, there are very few clay potteries like the Fuli clay pottery that have formed their own system during the thousands of years of their existence. As the decoration, the different lines on the surface of the Fuli clay pottery are in the same strain with the Chinese traditional lines and the crafts features.

$\mathrm{Xu}$ Wei, an outstanding painter, writer, artist and strategist in the Ming Dynasty, is almost universally known at that time. He advocated the aesthetic idea of "Be alike in spirit is more important than the shape" has similarities with the aesthetic taste and aesthetic pursuit of the Fuli clay pottery "The Great Lion". The unique decorative patterns, s-shaped lion's tail, curved eyebrows, and very distinctive nose let people have this visual feeling: at the first glance, it looks like a lion, but when looking at it in detail, it does not look like a lion. It also looks like a tiger, a dog, and a leopard. That is the reason why we describe this piece of Fuli clay pottery work as a unique one. The body of this piece of art work is simple structured and the lines are decorated smoothly. This work does not pay attention to the accurate modeling and the rigorous structure, but it is filled with the feeling of indomitable spirit and creates an implicit stance, that is why this work is so eyecatching. It is said that the Fuli clay pottery had participated in the "Folk Arts and Crafts Exhibition of Shandong Province in 1982" organized by the China Art Museum and the work of "The Great Lion" was also exhibited there. After careful study and heated discussions by the Chinese and foreign experts and scholars, the Fuli clay pottery works had been highly valued by them. The master piece "The Great Lion " displays a simple and lively charm, which was deeply into the hearts of the people living in the south of Shandong Province.

Another typical Fuli clay pottery work is "The Toad". It is one of the most produced one in the Fuli clay pottery family. We are no strangers to this animal, because the appearance of toad is very ugly, people tend to think this animal can counteract evil force and has a repellent effect. In the south of Shandong Province, especially in the Fuli village, the toad's moral is good weather, wealth and longevity. The shape of "The Toad" is unobtrusive and its body is like a big bump. From the details of the observation, we can see their eyes are small bumps and their front legs are simplified to bumps, covered with compact small bumps. These bumps are called "Ruding" in the folk culture. 
"Ruding" means circle, which is the model of universe and the laws of nature. As a kind of core image in human culture, "circle" has profound connotations. ${ }^{[5]}$ The shape and movement trajectory of the universe can be expressed as circles. Human's thoughts and their feelings of satisfaction can also be manifested as circles. It implies "harmony and unity", "subtle and gentle" and "perfection" ... Perhaps in the heart of the Fuli people, this irregular shape of "Ruding" implies their longings for healthy and happy life. The Fuli people use the "circle" culture to pass on wisdom, tolerance and positive energy. At the backs of the medium sized toad clay potteries, we can usually see the basrelief portrayed as the image of "jade rabbit pounding the medicine" or the word relief written as "ward off evil". The jade rabbit image is simple in lines, which reflects the simplicity and sincerity of the Fuli people. When looking at "The Toad" in detail, we can find more special features. For example, the rims of the two eyes are decorated with two symmetrical round circles and two hind paws under the belly are decorated with three horizontal lines and three vertical lines. In this way, the clay pottery work "The Toad" displays its unique features through the simple shape.

\subsection{Coloring-Natural Unity}

For Lao Tzu, "nature" is the core content of Taoism. According to the fifteenth chapter of Lao Tzu, "Human beings' actions will affect the earth, and then the heaven will be influenced. As a result, Taoism and nature will also be changed." ${ }^{6]}$ This shows that Lao Tzu explores nature while following the laws of nature. Philosophy of Chuang Tzu, on the basis of Lao Tzu philosophy, goes deeper to understand nature and emphasizes the nature of nature. By using natural phenomena to comprehend the moral of self-cultivation, he guides people to the liberation of life. "Maintaining the nature of nature" can be used to describe folk art works. Many people think that folk works are vulgar and do not appeal to refined taste. However, in my opinion, extreme vulgarity can become elegance and will be accepted by the public. This kind of vulgarity is not artificial but the true embodiment of creative work. Just as $\mathrm{Xu}$ Wei said: "The more vulgar, the more elegant." [7] Seemingly contradictory "vulgar" and "elegant" are in fact classified as unity. Fuli clay pottery works and $\mathrm{Xu}$ Wei's ink-and-wash paintings, though different from the artistic carriers that pursue the natural effects, are similar in their nature. It is true that the level of development of clay pottery is difficult to compare with that of Chinese painting. The craftiness of making craft is hardly comparable with that of elegant literati ceramics. However, the natural simplicity that folk clay potteries distribute is unique. It is also a proof of Zhuangzi's philosophy of maintaining a natural nature.

Gan Zhi made a great contribution to the rescue and excavation of Zaozhuang Fuli clay pottery. In order to promote the development of Fuli clay pottery, although Gan Zhi lacked the knowledge of geology and archeology, he studied hard and conducted a comprehensive research of the local unearthed pottery. Over the past 30 years, Gan has traveled to the villages around Fuli, searching for hundreds of pottery craftsmen. In the black pottery institute, which is located in Longshan town, Zhangqiu city, he found a black pottery lion. He was so fond of it that he brought it back home to fire the pottery and then compared with the pottery that he made by himself. After the experiment, he came to the conclusion that the Fuli clay can be sintered into black clay. In Fuli, the material for pottery is from nature. Its craftsmanship has a strong regional character, and these obscure pottery products are being created from these natural materials. Although made of clay, it is full of profound cultural history of China. "Lao Tzu" puts forward the view that "different colors can blind people and the noises can deafen people". Moreover, the "natural sound of Xiao" mentioned by "Zhuangzi" all show the nature of conforming to nature. Fire, as the weapon for people to conquer nature, is the medium of pottery. Fire increases the natural texture and color of the surface of pottery works in the changes of temperature and atmosphere of kiln fire. Fire also adds the mysterious features to the pottery and makes it a good explanation of the natural form.

The natural unity of the surface color of the Fuli clay pottery is determined by the nature of the soil and the firing process. The word "unification" here means to a certain extent that most of the pottery pots use their own color (not the glaze color) formed by firing different kinds of mud. It can be divided into red pottery, gray pottery, black pottery and white pottery by the ceramic and the 
color. The composition of clay has a certain impact on the firing of pottery and its color. The general clay contains iron compounds, thus can reduce the firing temperature of ceramic, showing red in the air oxidation and gray in the original environment. The blend of mud and fire makes the color of baked pottery natural and simple.

\subsection{Coloring-Natural Unity}

The word "Write" in "Write as the soul" can be summed up as paying attention to expressing the artist's personal feelings and taste. In the foregoing, the performance of the "freehand" trait is emphasized in the artist's hand, but more attention is paid to the expression of inner feelings, but at the same time, the performance of the skills is also pursued. Folk art works are the precious inheritance by the folk artists who inherit from his predecessors. It belongs to the past as well as the present and the future. It is a kind of dynamic and historical cultural accumulation. Much of the folk works are a medium for folk writers to express their inner thoughts and emotions. It's crude, simple and natural to show people the longing for a better life, also can be described as "writing as the soul."

The most prominent artistic feature of the Fuli clay pottery art is primitiveness. As a typical representative of Longshan culture, Pottery Gui-pitcher has distinctive primitive features under its beautiful shape. Fuli also had unearthed Pottery Gui-pitcher. According to the information of the Chinese Quintessence Dictionary, "Gui-pitcher is composed of spout, neck, abdomen, handle and legs. The whole shape is like a standing bird, so some scholars think this material is related to the ancient Dongyi worship of bird totem." Thus, the inspiration of the shape of Pottery Gui-pitcher may come from birds and beasts. Different from cans, tripods, pots and cups, Pottery Gui-pitcher replaced its abdomen with three spacious inverted conical legs, which will help increase storage capacity and heating rate, a beak-like spout to make it easier to pour water. Changing the previous shape of Pottery Gui-pitcher, more pursuit of the diversity of body structure, although Pottery Guipitcher is made by request of its practical features, the fluency of its outline lines and the pursuit of the natural beauty reflect the skillful craftsmanship of our ancestors. Just as Gan Zhiyou's song says, although the bag-legged Pottery Gui-pitcher is a cooker, it looks like a glorious eagle which makes people feel amazed.

"Gentle quiet foliage pattern, winking stars in the sky, the three-legged bird post is the god of fire and the horns were actually the emperor's totem. Rapid rotation of the swirl lines, clouds, water, dancing people, running horses and the buffalo-shaped wine vessels are full of life scenes of our ancestors. "These few words seem to show us that the clay pottery can be in dialogue with history. Like the typical decorative patterns in folk art, such as the nails pattern, whirlpool lines, lines and stripes, as well as the ancient animal and plant totems, figure patterns, astronomical phenomena, like people, lions, horses, birds, toads, leaves, chrysanthemums, the sun, the moon, stars and water all reflect the diversity of the objects painted on the Fuli clay pottery, which not only can bring rich visual experience to people, but also have very rich artistic and cultural connotations. Fuli clay pottery expresses the external beauty of the objects through the intrinsic nature under the premise of the unity of the aesthetic subjects and aesthetic objects. Fuli clay pottery takes natural objects as a carrier to highlight the essence of pottery art, the combination of practicability and aesthetic reflects the ancestors' pursuit of natural beauty.

In the modern Fuli clay pottery, there are potteries made and sintered with the use of molds, there are potteries modelled with bare hands, and there are potteries glazed with gorgeous colors. The function of sacrificing in the past have eclipsed, but the potteries' role in showing the Chinese nation's spirit, in appreciation and amusement become more and more significant. "Harmony" can be said to be an eternal topic, it is not only stuck in the harmony between people, the harmony between man and nature, etc. In modern art, harmony between "natural material" and "aesthetic spirit", harmony between "performance language" and "artistic individuality" can also be included. However, contrary to the harmonious artistic creation, it is not uncommon to find that individual creators do not fully understand the differences between Chinese and Western cultures and do not completely digest and absorb the connotation of local cultural spirits. Therefore, the so-called works, 
which deviate from the social background of the national culture and subjectively imagine or follow the trend of the development of western modern ceramic art, will lose the value of existence as ceramic art works. The art of harmony will then become a piece of paper talk.

\section{Conclusion}

Fuli clay pottery materialized nationalistic totem, expressed the spirit of the objects in the freehand, subtly reflected people's thoughts and feelings of life and perception, so that artistic image, such as painting, sculpture, dance, folk art, etc. have reached the fusion of material and spiritual and obtained sublimation. To a certain extent, Fuli clay pottery's artistic characteristics trait equals to its cultural character. In the development of the times, it suffered from such factors as politics, economy, nature and geography, causing its development to be in an unstable state, lacking in profound connotation and elegant style.

However, it still reflects the traditional spirit of the Chinese nation as well as the local complex, which has certain value for research and promotion. If a nation or a region wants to have a culture and art with national characteristics all along, it needs to rely on the social background of its own culture and continue to maintain and inherit the original cultural features while preserving its irreplaceable tradition of art making. At the same time, efforts should be made to explore effective ways suitable for the cultural development in this region, excavate the application fields of folk Fuli clay pottery art creatively, make more people pay attention to and protect the clay pottery art in Zaozhuang, which has a high practical significance to the creation of Zaozhuang regional culture and systematic artistic expression..

\section{Acknowledgements}

Fund projects: Shandong art education subject "Based on the fine arts education of cultivating the ability of across studies”(project number: YJ201612126)

Teaching reform project of Zaozhuang University”Study on the reform of pre-school education manual teaching in the training mode of applied talents"(YJG1502)

Hu Chenchen, Zaozhuang University,Zaozhuang 277100, ChinaEmail: 304704808@qq.com Tel:15949952956

\section{References}

[1] Z. Baihua, The Complete Works of Zong Baihua, vol. 2, Hefei: Anhui Education Press, 1994.

[2] X. Zhengnong and C. Zhili, Cihai, Shanghai: Shanghai Dictionary Publishing House, 2010.

[3] S. Guoqiang, Painting History of Ming Dynasty, Beijing: People's Fine Arts Publishing House, 2001.

[4] F. Jingsheng, China Freehand Painting and Calligraphy, Zhengzhou: Henan Fine Arts Publishing House, 2005.

[5] H. Fang and S. Jinsong, Gan Zhiyou and his Fuli Clay Pottery, Beijing: Culture and Arts Publishing House, 2004..

[6] Lao Tzu, Beijing: Zhonghua Book Company, 2008..

[7] X. Wei, Collection of Xu Wei, vol. 4, Beijing: Zhonghua Book Company, 1983.

[8] Y. Lang, Outline of Chinese Aesthetic History, Shanghai: Shanghai People's Publishing House, 1985.

[9] H. Deliang, Zaozhuang Jianxin: Excavation Report of Neolithic Sites, Beijing: Science Press, 1996.

[10] H. Hui, "Modeling and Decorative Features of Fuli Clay Pottery," 
[11] Beauty and Times, pp. 63-64, February 2015.

[12] Z. Bin, The Formation of the Black Aesthetic Tradition in Ancient Chinese Ink Painting, Journal of Kashgar Teachers College, vol. 2, 2007. 